\title{
Perancangan Sistem Parkir Pada Gedung Menara Palma Jakarta
}

\author{
Anggi Oktaviani $^{1}$; Dahlia Sarkawi ${ }^{2}$; Agus Priadi ${ }^{3}$ \\ ${ }^{1}$ STMIK Nusa Mandiri Jakarta \\ ${ }^{2}$ Universitas Bina Sarana Informatika \\ ${ }^{3}$ Universitas Bina Sarana Informatika \\ 1ªnggi.aov@ nusamandiri.ac.id
}

\begin{abstract}
Parking pool or parking area is a place provided for parking of motorized vehicles outside of the road whih is provided by individual or institution, including motorized vehicle storage and motorized vehicle garage. In managing the parking pool, the parking owner must have a system to facilitate the processing of the parking area. The existing parking system at Palma tower building Jakarta is still manual, that is by entering the vehicle number into the computer by operator, then printing. The parking ticket provided is only a form of paper containing the vehicle number and vehicle entry time. Payment transactions method made by parking operators are currently not efficient, because the level of officer error when calculate parking fees and change money is high. Deal with these various problems, an idea arises to create a subscription parking system by using an automated parking system. This automated parking system is named with an RFID system (Radio Frequency Identification). The design of this automatic parking system is the best option to soling the problems that are already running. This computerized standard system is better than a non computerized system because this system can run more optimally and it is more convenient than the previous system.
\end{abstract}

Keywords: Parking system designing, RFID, visual basic 6.0 dan Mysql

\begin{abstract}
ABSTRAK
Tempat parkir atau lahan parkir merupakan tempat yang disediakan untuk parkir kendaraan bermotor di luar badan jalan yang disediakan oleh orang atau badan, termasuk tempat penitipan kendaraan bermotor dan garasi kendaraan bermotor. Dalam mengelolah tempat parkir, pemilik parkir harus memiliki sistem untuk mempermudah pengolahan tempat parkir tersebut. Sistem parkir yang sudah ada saat ini pada gedung Menara Palma Jakarta masih bersifat manual, yaitu dengan cara operator masuk menginput nomor kendaraan ke dalam komputer, kemudian di print. Karcis parkir yang diberikan pun hanya berupa kertas yang berisikan nomor kendaraan dan jam masuk kendaraan. Transaksi pembayaran yang dilakukan oleh operator parkir saat ini kurang efisien, karena tingkat kesalahan petugas saat menghitung biaya parkir dan uang kembalian terbilang tinggi. Dengan adanya berbagai masalah tersebut maka timbul ide untuk membuat suatu sistem parkir berlangganan dengan menggunakan sistem otomatis parkir. Sistem otomatis parkir ini dinamakan dengan sistem RFID (Radio Frequency Indentification). Perancangan sistem parkir otomatis ini adalah pilihan terbaik untuk solusi dari kendala-kendala yang sudah berjalan. Sistem yang sudah berstandar komputer tersebut lebih bagus dari sistem yang belum otomatis karena sistem ini dapat berjalan lebih optimal serta sistem otomatis ini lebih layak dibandingkan dengan sistem yang pendahulunya.
\end{abstract}

Kata kunci: Perancangan sistem parkir, RFID, visual basic 6.0 dan Mysql 


\section{PENDAHULUAN}

Di era teknologi ini dunia diharapkan oleh pertumbuhan teknologi yang sangat baik dari qaktu ke waktu. Pertumbuhann ilmu pengetahuan dan sains yang kian menaik khususnya di bidang elektronik diawali dengan naiknya perkembangan yang timbul dengan dibuatnya peralatan elektronik yang kian modern. Banyak kegunaan yang didapat dari pertumbuhan pada bidang elektronik itu, salah satunya yauitu kian ringannya manusia untuk menuntaskan kendala maupun berbuat sesuatu yang akhirnya waktu, daya dan pengeluaran bisa dikerjakan dengan lebh optimal. pekerjaan yang dikerjakan terus menerus saat ini sudah ditukar oleh alat-alat yang dibuat dengan modern, yang bisa beroprasi tanpa melibatkan daya manusia. Seiring kian bertumbuhnya teknologi kian banyak pula tindakan kejahatan diantaranya seperti pencurian dan lain-lain. Apalagi sekarang ini, perampasan kendaraan bermotor yang biasa disingkat sebagai curanmor menduduki puncak teratas perbuatan kejahatan. Karenanya seyogyanya dapat diciptakan sistem sekuritas di kendaraan bermotor dan pencegahan hal-hal yang buruk, terlebih lagi sekuritas parkir contohnya pada mal, gedung kantor, sekola, kampus, dan sebagainya yang menjadikan parkir adalah lokasi utama bagi pengendara menempatkan kendaraannya.

Area parkir dan sistem sekuritas parkir adalah bagian utama dan tidak boleh dipecahkan dalam servis sebuah sarana umum. Kehadiran sistem perparkiran yang bagus akan mensupport sarana umum yang dipakai oleh pihak lain. konfigurasi parkir yang bagus menlukiskankan kelayakann sistem yang semakin, karenanya sekuritas dan kepuasan adalah hal yang diinginkan oleh pemakai sarana umum. Jika sistem parkiran tidak menjamin sekuritas, tidak menyulitkan, dan kepuasan bagi pemakai sarana umum, akan menyebabkan kinerja dalam sarana umum tersebut. Besarnya sarana umum yang tetap memakai metode parkir kuno pada pintu masuk utama tempat parkir nya. Konfigurasi inventarisasi dan validasi yang digunakan secara kurang benar maka kegiatan dalam sarana umum tersebut akan terkendalau. Penentuann metode servis yang benar pada sistem parkiran akan menempatkan sekuritas, keringkasan dan kepuasann sarana umum tersebut. Sistem inventarisasi dan validasi yang dipakai adalah metode tiket kuno, yaitu dengan menulis menginput plat nomor kendaraan pada komputer kemudian di print.

Penulis akan melakukan perancangan sistem otomatis parkir yang dapat mengurangi kendala sistem sekuritas parkir yang telah berjalan. Penulis menciptakan konfiguraso sistem parkir otomatis dengan menggunakan sistem RFID(Radio Frequency Identification), yang mana sistem ini bisa melakukan otentikasi di kendaraan dan si pemilik dengan canggih tidak melibatkan petugas parkir yang memantau langsung. Sistem dapat memperlihatkan tanda waktu pada saat keluar dan masuk kendaraan agar informasi yang didapat lebih detail.

\section{METODE/PERANCANGAN PENELITIAN}

\subsection{Konsep Dasar Sistem}

Harfiahnya, suatu sistem bisa tafsirkan dengan satu gabungan atau ikatan yang terdiri dari bagian, partikel, atau variabel yang tertata, berinteraksi satu sama lain, membutuhkan satu sama lain dan terpadu, bak halnya informasi pada suatu perusahaan yang paling utama untuk menopang kelangsungan pertumbuhannya, karenanya ada argumen bahwa informasi sangat diperlukan oleh suatu perusahaan. Dampak jika kurang terpenuhinya informasi, dalam masa tertentu perusahaan akan merasakan ketidak cakapan mengatur sumber daya, akhirnya dalam menentukan kebijakankebijakan strategis makin terkendala, yang alhasil akan menjalani kegagalan dalam persaingan dengan lawan bisnisnya. Selain itu, sistem informasi yang dipunya acap kali belum dapat dijalankan secara optimal sehingga akhir yang diperoleh kurang maksimal. 
Secara sederhana, suatu sistem dapat diartikan sebagai suatu kumpulan atau himpunan dari unsur, komponen, atau variabel yang terorganisir, saling berinteraksi, saling tergantung satu sama lain dan terpadu, seperti halnya informasi di dalam sebuah perusahaan yang sangat penting untuk mendukung kelangsungan perkembangannya, sehingga terdapat alasan bahwa informasi sangat dibutuhkan bagi sebuah perusahaan. Akibat bila kurang mendapatkan informasi, dalam waktu tertentu perusahaan akan mengalami ketidakmampuan mengontrol sumber daya, sehingga dalam mengambil keputusan- keputusan strategis sangat terganggu, yang pada akhirnya akan mengalami kekalahan dalam bersaing dengan lingkungan pesaingnya. Disamping itu, sistem informasi yang dimiliki seringkali tidak dapat bekerja dengan baik.

\subsection{Pengertian sistem}

Menurut [1], sistem adalah selengkap unsur yang berkorelasi satu sama lain dan saling mempengaruhi dalam suatu konteks tertentu.

Sedangkan menurut [2]"ditemukan dua gabungan penghampiran sistem dalam menentukan siste, yaitu penghampiran pada prosedur dan penghampiran pada komponen-komponen, serta elemen- elemen".

\subsection{Definisi Sistem}

Menurut [3], definisi sistem adalah sebagai kumpulan komponen yang berinteraksi membentuk suatu kesatuan dan keutuhan yang komplek didalam tingkat tertentu untuk mengejar tujuan yang umum.

Sedangkan menurut Mulyanto dalam [4], "mendefinisikan sistem dalam bidang sistem informasi sebagai "Sekelompok komponen yang saling berhubungan, bekerja sama, untuk mencapai tujuan bersama dengan menerima proses input serta menghasilkan input dalam proses transformasi yang teratur".

\subsection{Pengertian informasi}

Menurut [1], informasi adalah melukiskan hasil prosedur data yang didapat dari tiap unsur sistem tersebut sebagai bentuk yang gampang dimengerti dan membentuk kepandaian yang relevan dan diperlukan dalam penafsiran fakta-fakta yang ada. Informasi menggambarkan himpunan data yang telah diproses oleh data bersifat kualitatif maupun kuantitatif dan memiliki pemahaman yang lebih besar.

\subsection{Pengertian Parkir}

Menurut [5], "Parkir adalah keadaan tidak bergerak suatu kendaraan yang tidak bersifat sementara. Termasuk dalam pengertian parkir adalah setiap kendaraan yang berhenti pada tempattempat tertentu baik yang dinyatakan dengan rambu ataupun tidak, serta tidak semata-mata untuk menaikkan dan atau menurunkan barang dan atau orang.

Parkir merupakan suatu kebutuhan bagi pemilik kendaraan dan menginginkan kendaraannya parkir ditempat. Dimana tempat tersebut mudah untuk dicapai. Kemudahan yang diinginkan tersebut salah satunya adalah parkir di badan jalan. Untuk itu pola parkir yang ada di badan jalan adalah pola parkir paralel dan menyudut Akan tetapi tidak seialu parkir di badan jalan diizinkan, karena kondisi arus lalu lintas yang tidak memungkinkan.

\subsection{Visual Basic}

Menurut Sunyoto dalam [2], "Visual Basic adalah program untuk membuat aplikasi berbasis microsoft windows secara cepat dan mudah". Visual Basic menyajikan alat untuk pembuatan aplikasi simpel sampai aplikasi rumit baik untuk kepentingan sendiri ataupun untuk kepentingan bisnis dengan konfigurasi yang lebih luas. "Visual" untuk kata ini menggambarkan literasi pemograman yang memberi beraga, desain dengan GUI (Grapichal User Interface). Cukup dengan menuliskan tidak banyak kode program. Progmer telah bisa memakai program dengan bentuk yang 
menawan. "Basic" Menampakan literasi pemograman BASIC (Beginner all- Purpose Symbolic Intruction Code). Visual Basic dimulai dari bahasa BASIC yang ditambah ribuan perintah baru, function, keyword, dan banyak berkaitan langsung dengan GUI windows.

\subsection{XAMPP}

Menurut Madcoms dalam [6], "Xampp adalah sebuah paket kumpulan software yang terdiri dari Apache, MySQL, phpMyAdmin, PHP, Perl, Filezilla dan lain-lain yang berfungsi untuk memudahkan instalasi lingkungan PHP, dimana biasanya lingkungan pengembangan web memerlukan PHP, Apache, MySQL, dan phpMyAdmin serta software lainnya yang terkait dengan pengembangan web.

Sedangkan menurut [7], XAMPP adalah fasilitas untuk banyak sistem operasi seperti Windows, Linux, Mac, dan Solaris yang memungkinkan sebuah web dinamis bisa diakses secara local menggunakan web server local.

\subsection{MYSQL}

Menurut Kadir dalam [8], "MYSQL adalah salah satu jenis database server yang menggunakan SQL sebagai bahasa dasar untuk mengakses databasenya. Dengan menggunakan script PHP dan PERL Software database ini dapat berfungsi atau berjalan pada semua platform sistem operasi yang biasa digunakan (Windows, Linux, OS/2, berbagai varian Unix)".

\subsection{Basis Data}

Menurut [9], basis data adalah sistem dengan standar komputer yang target utamanya yaitu merawat data yang sudah diproses atau informasi dan mempersiapkan informasi yang ada saat diinginkan. Pada dasarnya adalah wadah untuk menyimpan data agar dapat digunakan dengan gampang dan cepat.

\subsection{Pengembangan perangkat lunak}

Menurut [9], Model SDLC air terjun (Waterfall) acap kali disebut model sekuensi linier (sequential linear) atau alur hidup klasik (classic life cycle). Model air terjun menyajikan penghampiran alur hidup perangkat lunak selaku sekuensial atau terurut diawali dari analisis, desain, pengkodean, pengujian dan tahap pendukung (support).

Tahapan-tahapan yang ada pada SDLC secara global ada Inisiasi (initiation), Pengembangan konsep sistem (system concept development), Perencanaan (planning), Analisis kebutuhan (requirements analysis), Desain (design) Pengembangan (development), Integrasi dan pengujian (integration and test), Implementasi (implementation), Operasi dan pemeliharaan (operation and maintanence), Disposisi (disposition). SDLC mempunyai sejumlah model dalam pelaksanaan tingkatan prosesnya. Salah satunya adalah model Waterfall.

1. Analisa Kebutuhan Perangkat Lunak

Proses pengambila kebutuhan dikerjakan secara intens demi mendetailkan keperluan perangkan lunak agar bisa dimengerti perangkat lunak seperti apa yang diinginkan oleh user. Pendetailan kebutuhan perangkat lunak pada tingkatan ini perlu diarsipkan.

2. Desain

Desain perangkat lunak merupakan prosedur banyak langkah yang berinti pada desain pembentukan program perangkat lunak tercantum struktur data, arsitektur perangkat lunak, representasi antarmuka, dan prosedur pengodean. tingkatan ini menerjemahkan kebutuhan perangkat lunak dari tingkat analisis kebutuhan ke representasi desain supaya bisa dterapkan sebagaii program pada tingkatan selanjutnya

3. Pembuatan kode Program

Desain harus terjemahkan ke dalam program perangkat lunak. Tujuan dari tingkatan ini yaitu program komputer sinkron dengan desain yang sudah diciptakan pada tigkat desain. 


\section{Pengujian}

Pengujian berinti pada perangkat lunak dari segi logika dan fungsional dan memantapkan bahwa seluruh komponen telah dinilaii. Hal ini dikerjakan untuk mengurangi kesalahan (error) dan memantapkan output yang diciptakan sinkron dengan yang diperlukan.

5. Pendukung (support) atau pemeliharaan (maintenance)

Tidak menutup probabilitas satu perangkat lunak menjalanai alterasi saat telah disampaikankan ke user. Alterasi dapat terjadi disebabkan adanya kesalahan yang timbul dan tidak terjangkau saat testing atau perangkat lunak seyogyanya dapat menyesuaikan diri dengan kodisi baru.

\subsection{Teori Pendukung}

1. Entity Relationship Diagram (ERD)

Menurut Dhanta dalam [4], "Entity Relationship Diagram (ERD) yaitu model konseptual yang Menjabarkan hubungan antara penyimpanan data dan hubungan data".

Notasi-notasi simbolik di dalam Diagram ERD yang dapat kita gunakan adalah sebagai berikut:

\section{Logical Record Strunture (LRS)}

Menurut Dhanta dalam [4], "LRS (Logical Record Structure) adalah representasi dari struktur record- record pada tabel-tabel yang terbentuk dari hasil antar himpunan entitas. Menentukan kardinalitas, jumlah table dan Foreign Key (FK)".

Disimilaritas LRS dan ERD serta tipe record bertempat diluar field tipe record berada. LRS tersusun dari link-link disekitar tipe record. Link ini memperlihatkan arah dari satu tipe record lainnya. Banyak link dari LRS yang dikasih simbol field-field yang terlihat pada kedua link type record.

1) Unified Modelling Language

a. Definisi Unified Modelling Language

Menurut Whitten \& Bentley dalam [10], "Unified Modeling Language (UML) versi 2.0 adalah sekumpulan konversi pemodelan yang digunakan untuk menentukan atau menggambarkan sebuah sistem software yang terkait dengan objek".

b. Activity Diagram

Menurut [9], diagram aktivitas atau activity diagram melukiskan workflow (aliran kerja) atau aktivitas dari satu konfigurasi atau proses bisnis atau menu yang terdapat di perangkat lunak.Yang harus diberikan atensi dalam hal ini adalah diagram aktivitas mendeskripsikan aktivitas sistem tidak dengan yang dikerjakan aktor, jadi aktivitas yang dapat dilakukan oleh sistem

c. Uce Case Diagram

Menurut [9], use case atau diagram use case yaitu pemodelan untuk kelakuan (behavior) sistem informasi yang akan diciptakan. Use case menggambarkan suatu interaksi antara satu atau lebih aktor melalui sistem informasi yang akan diciptakant. Secara sederhana, use case dipakai bertujuan memahami fungsi apa saja yang ada di dalam satu sistem informasi dan siapa saja yang mempunyai wewenang menjalankan fungsi-fungsi itu.

Sedangkan menurut Satzinger et al dalam [11], menyatakan bahwa, "Use Case Diagram adalah suatu aktivitas yang dilakukan oleh sistem, biasanya merupakan sebuah respon untuk permintaan dari pengguna sistem".

Simbol-simbol use case diagram seabgai berikut: 


\section{d. Class Diagram}

[9], "Diagram kelas atau class diagram menggambarkan struktur sistem dari segi pendefinisian kelas-kelas yang akan dibuat untuk membangun sistem". Kelas memiliki apa yang disebut atribut dan metode atau operasi. Sequence Diagram

[9], diagram sequence menggambarkan kelakuan objek pada use case dengan mendeskripsikan waktu hidup objek dengan massage yang dikirimkan dan diterima antar objek. Oleh karena itu utuk menggambarkan diagram sequence maka hrus diketahui objek-objek yang terlibat dalam sebuah use case beserta metode-metode yang dimiliki kelas yang diinstansikan menjadi objek itu.

\section{HASIL DAN PEMBAHASAN}

\subsection{Tahapan perancangan sistem}

\subsubsection{Analisa kebutuhan}

Dalam sistem RFID ini terdapat 4 pengguna yang saling berinteraksi dalam lingkungan sistem, yaitu: Admin, operator, pengunjung umum, pelanggan. Keempat pengguna tersebut mempunyai karakteristik interaksi dengan sistem yang berbeda-beda dan memiliki kepentingan informasi yang berbeda-beda, seperti berikut:

1. Skenario Kebutuhan Admin:

a) Admin melakukan login sebelum masuk kehalaman utama.

b) Admin melakukan pencarian data transaksi dan membuat laporan data transaksi kendaraan pengunjung umum.

c) Admin melakukan pengelolaan data member baik menambahkan, mengubah, dan menghapus data member

d) Admin melakukan pendaftaran pelanggan.

2. Skenario Kebutuhan Pelanggan:

a) Melakukan pendaftaran sebagai pelanggan

b) Membayar biaya parkir.

3. Kebutuhan Sistem

Kebutuhan masukan atau input yang diperlukan untuk memenuhi kebutuhan dalam pembuatan perangkat lunak ini, antara lain:
a) Pelanggan scanning kartu.
b) Sistem akan membaca kartu pelanggan.
c) Palang pintu akan terbuka secara otomatis.

\subsubsection{Rancangan Dokumen Sistem Usulan}

\section{Spesifikasi Bentuk Dokumen Masukan}

Dokumen input atau dokumen masukan adalah sebagai bentuk masukan berupa dokumen yang diolah didalam proses untuk menghasilkan sesuai yang diharapkan. Adapun dokumen masukan yang dibutuhkan adalah sebagai berikut:

$\begin{array}{ll}\text { 1) Nama Dokumen } & \text { : Form Pendaftaran Pelanggan } \\ \text { Fungsi } & \text { : Sebagai Pelanggan Parkir } \\ \text { Sumber } & \text { : Pemilik Kendaraan } \\ \text { Tujuan } & : \text { Bagian Administrasi } \\ \text { Media } & : \text { Kertas } \\ \text { Jumlah } & : \text { 1 Lembar } \\ \text { Frekuensi } & : \text { Setiap kali melakukan pendaftaran pelanggan } \\ \text { Bentuk } & : \text { Lampiran C.1 }\end{array}$


2) Nama Dokumen : STNK

$\begin{array}{ll}\text { Fungsi } & : \text { Pembuatan kartu parkir } \\ \text { Sumber } & : \text { Pelanggan } \\ \text { Tujuan } & : \text { Bagian Administrasi } \\ \text { Media } & : \text { kertas } \\ \text { Jumlah } & : \text { lembar } \\ \text { Media } & : \text { Kertas } \\ \text { Frekuensi } & : \text { Setiap kali Pembuatan kartu parkir } \\ \text { Bentuk } & : \text { lampiran C.2 }\end{array}$

2. Spesifikasi Bentuk Dokumen Keluaran

Bentuk dokumen keluaran adalah segala macam bentuk laporan atau hasil proses input pada system pengolahan data pasien. Adapun bentuk dokumen keluaran yang dibutuhkan adalah sebagai berikut:

1) Nama Dokumen

Fungsi

: Kartu Pelanggan

Sumber

: Sebagai kartu tanda pelanggan

Tujuan

: Pelanggan

Media

: Bagian Administrasi

Jumlah

: Kartu

Frekuensi

: 1 Kartu

Bentuk

: Satu kendaraan

2) Nama Dokumen

: Lampiran D.1

Sumber

: Kwintasi

Tujuan

: Bagian Administrasi

Fungsi

: Pelanggan

Media

: Bukti pembayaran member

: Kertas

3) Nama Dokumen

: Laporan pembayaran member

Sumber

: Bagian Customer Service

Tujuan

: Pimpinan

Fungsi

Media

: Mengetahui jumlah member yang memesan

: Kertas

\subsection{Perancangan Perangkat Lunak}

\subsubsection{Spesifikasi File}

Spesifikasi file menjelaskan tentang file-file yang akan digunakan dalam perancangan sistem usulan parkir yang diajukan dan sebagai penyimpanan data.

1) Spesifikasi File Admin

$\begin{array}{ll}\text { Nama File } & : \text { Admin } \\ \text { Akronim } & : \text { Admin } \\ \text { Fungsi } & : \text { Untuk melak } \\ \text { Tipe File } & : \text { File master } \\ \text { Media } & : \text { Harddisk } \\ \text { Panjang record } & : \text { : } 0 \text { karakter } \\ \text { Kunci Field } & : \text { user_Admin } \\ \text { Software } & : \text { Mysql }\end{array}$

Tabel 1. Spesifikasi File Admin

\begin{tabular}{|c|l|l|l|l|l|}
\hline NO & \multicolumn{1}{|c|}{ Elemen data } & Nama Field & \multicolumn{1}{|c|}{ Tipe } & \multicolumn{1}{c|}{ Size } & Keterangan \\
\hline 1 & User admin & User_admin & Char & 10 & Primary key \\
\hline 2 & Pass admin & Pass_admin & Varchar & 20 & \\
\hline 3 & Nama admin & Nama_admin & Varchar & 30 & \\
\hline
\end{tabular}


2) Spesifikasi File

Nama File

: Operator

Akronim

: Operator

Fungsi

: Untuk melakukan login Operator

Tipe File

Media

: File master

Panjang record

: Harddisk

Kunci Field

: 82 karakter

Software

: user_Operator

: Mysql

Tabel 2. Spesifikasi File Operator

\begin{tabular}{|c|l|l|l|l|l|}
\hline NO & Elemen data & Nama File & Tipe & Size & Keterangan \\
\hline 1 & User name & User_name & Char & 10 & Primary key \\
\hline 2 & Pass operator & Pass_word & Char & 25 & \\
\hline 3 & Nama & Nama & Char & 15 & \\
\hline 4 & Nip & Nip & Char & 20 & \\
\hline 5 & Telepon & Telpon & Char & 12 & \\
\hline
\end{tabular}

3) Spesifikasi File Pelanggan

Nama File

Akronim

: Pelanggan

Fungsi

: Pelanggan

Tipe File

: Untuk menyimpan data pelanggan

Media

File master

Panjang record

: Harddisk

Kunci Field

: 78 karakter

Software

: Id_Pelanggan

: Mysql

Tabel 3. Spesifikasi File Pelanggan

\begin{tabular}{|c|l|l|l|l|l|}
\hline NO & Elemen File & Nama Field & Tipe & Size & Keterangan \\
\hline 1 & Id kartu & Id_kartu & Int & 7 & Primary key \\
\hline 2 & Nama & Nama & Char & 25 & \\
\hline 3 & Alamat & Alamat & Char & 30 & \\
\hline 4 & Telepon & Telepon & Char & 12 & \\
\hline 5 & No polisi & No_polisi & Char & 4 & \\
\hline 5 & Status & Status & Enum & 'In'.'Out' & \\
\hline
\end{tabular}

4) Spesifikasi File Pendaftaran

Nama File

: Pendaftaran

Akronim

: Pendaftaran

Fungsi

: Untuk menyimpan data pendaftaran

Tipe File

File master

Media

: Harddisk

Panjang record

: 77 karakter

Kunci Field

: No_Pendaftaran

Software

: Mysql 
Tabel 4. Spesifikasi File Pendaftaran

\begin{tabular}{|c|l|l|l|l|l|}
\hline No & Elemen data & Nama Field & Tipe & Size & Keterangan \\
\hline 1 & No pendaftaran & No_pendaftaran & Char & 6 & Primary key \\
\hline 2 & No polisi & No_polisi & Char & 10 & \\
\hline 3 & Nama & Nama & Char & 12 & \\
\hline 4 & Alamat & Alamat & Char & 30 & \\
\hline 5 & $\begin{array}{l}\text { Tanggal } \\
\text { pendaftaran }\end{array}$ & $\begin{array}{l}\text { Tanggal_Pendafta } \\
\text { ran }\end{array}$ & Date & DD/MM/YY & \\
\hline 6 & No telepon & No_Telepon & Char & 12 & \\
\hline 7 & No STNK & No_STNK & Char & 7 & \\
\hline
\end{tabular}

5) Spesifikasi File Transaksi

$\begin{array}{ll}\text { Nama File } & : \text { Transaksi } \\ \text { Akronim } & : \text { Transaksi } \\ \text { Fungsi } & : \text { Untuk menyimpan data transaksi } \\ \text { Tipe File } & : \text { File master } \\ \text { Media } & : \text { Harddisk } \\ \text { Panjang record } & : \text { 41 karakter } \\ \text { Kunci Field } & : \text { No_Transaksi } \\ \text { Software } & : \text { Mysql }\end{array}$

Tabel 5. Spesifikasi File Transaksi

\begin{tabular}{|c|l|l|l|l|l|}
\hline NO & Elemen data & Nama Field & Tipe & Size & Keterangan \\
\hline 1 & No polisi & No_polisi & Int & 4 & Primary key \\
\hline 2 & Nama & Nama & Char & 15 & \\
\hline 3 & Id kartu & Id_kartu & Char & 5 & \\
\hline 4 & $\begin{array}{l}\text { Tanggal } \\
\text { transaksi }\end{array}$ & Tanggal_Transaksi & Date & DD/MM/YY & \\
\hline 5 & No STNK & No_STNK & Char & 7 & \\
\hline 6 & Pembayaran & pembayaran & Char & 10 & \\
\hline
\end{tabular}

\subsection{Rancangan Program}

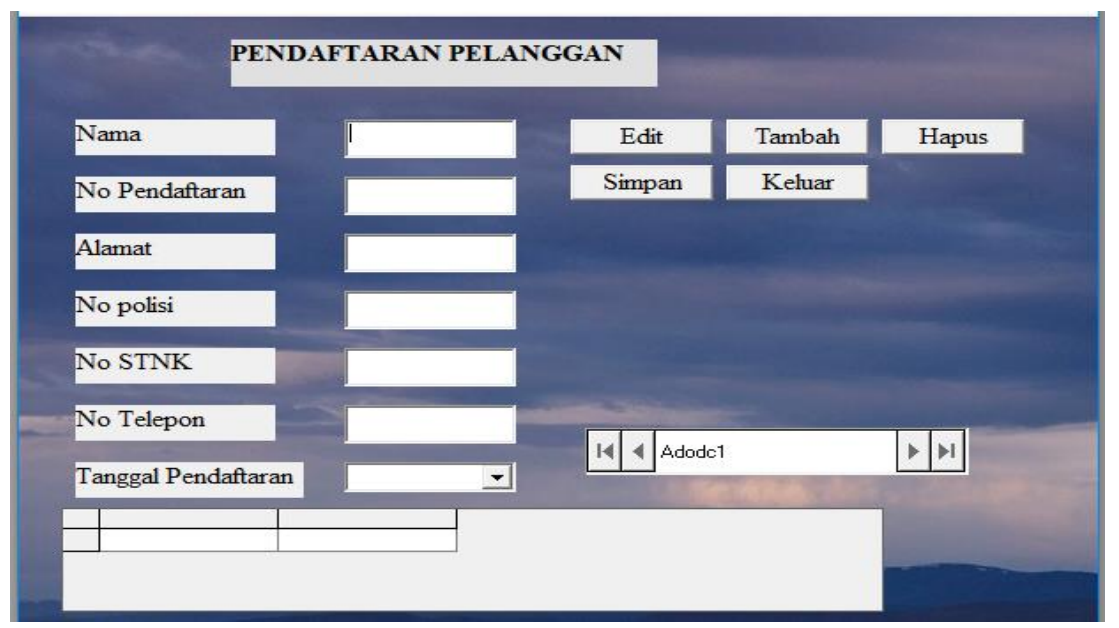

Gambar 1. Pendaftaran Pelanggan 


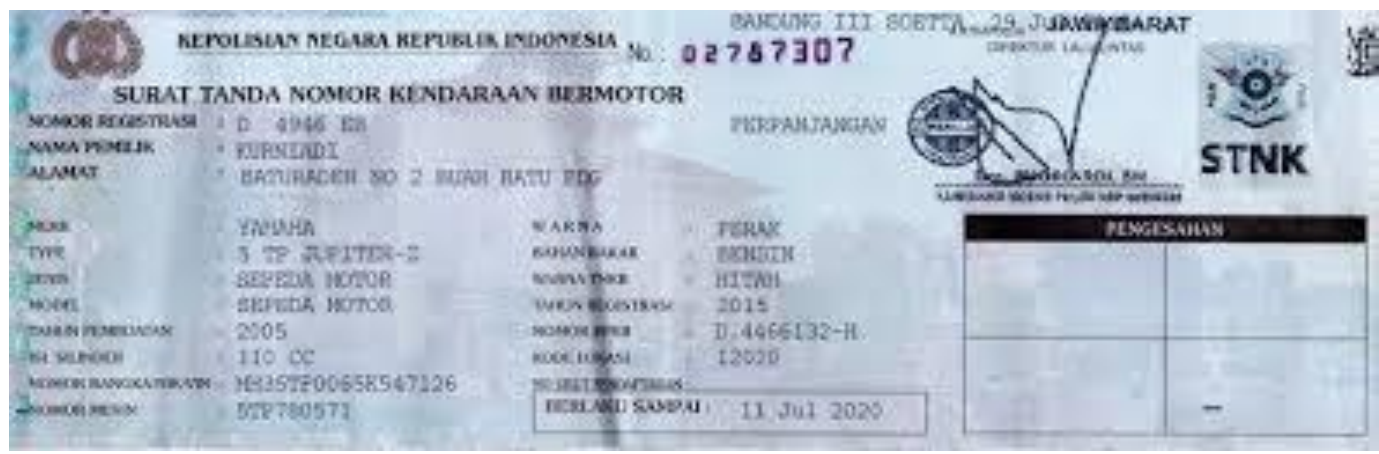

Gambar 2. STNK Pelanggan yang diinput

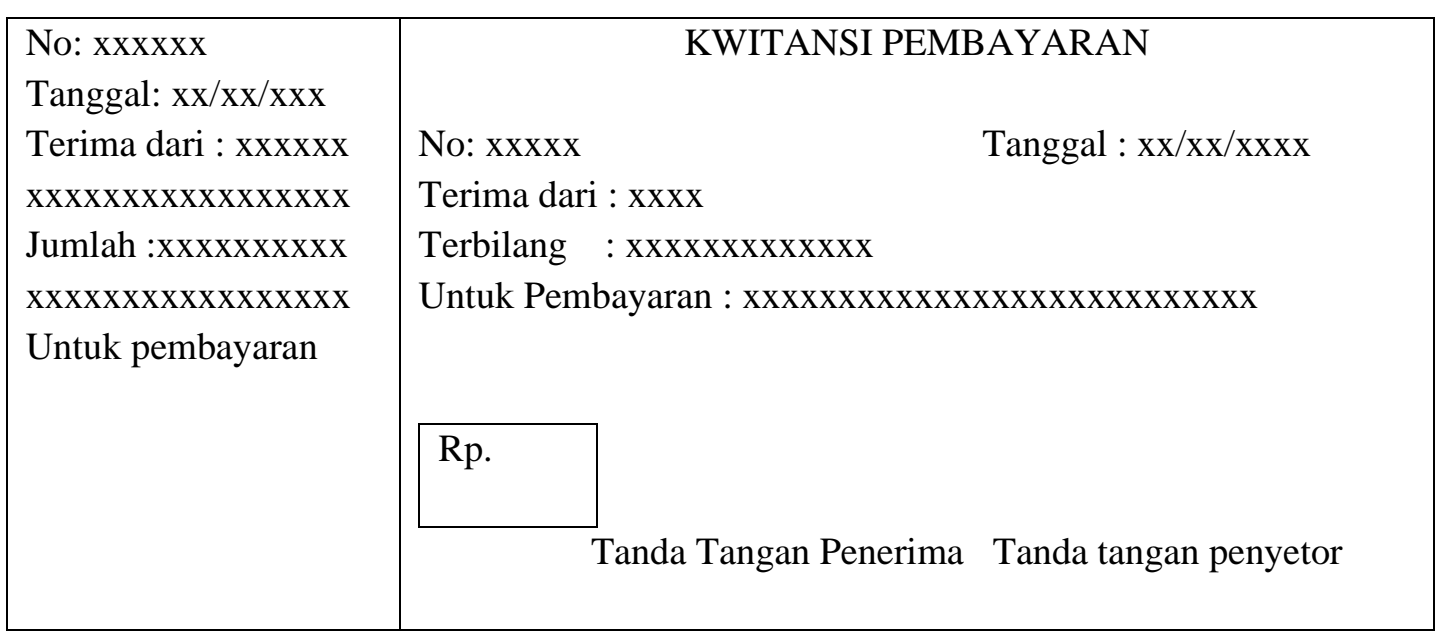

Gambar 3. Rancangan Kwitansi Pelanggan

\section{KESIMPULAN DAN SARAN}

\subsection{Kesimpulan}

Dengan adanya pengkajian ini maka penulis dapat menarik beberapa kesimpulan yaitu:

1. Dapat mempermudah proses masuk dan keluarnya kendaraan.

2. Perancangan sistem informasi perparkiraan tersebut, maka dapat mempermudah proses perhitungan biaya parkir.

3. Dengan adanya proses pendaftaran pelanggan ke dalam sistem, maka pengelolah parkir dapat mengetahui data pelanggan dengan akurat. Hal ini berfungsi sebagai rekap data pengelolah parkir bila ditemukan sebuah masalah yang membutuhkan data pelanggan.

4. Dapat mengefisiensikan waktu dalam hal perparkiran, serta mempermudah dalam hal pembuatan laporan

Data-data yang berkorelasi dengan sistem parkir akan lebih terjamin sekuritasnya, karena penyimpanannya sudah terkomputerisasi.

\subsection{Saran}

Dari kesimpulan yang telah dijelaskan, penulis memberikan saran yang sekiranya mungkin dapat dimanfaatkan dan dijadikan pedoman. Adapun saran-saran yang penulis sampaikan yaitu:

1. Pendaftaran pelanggan baru dapat dilakukan pada website. Sehingga setelah data pelanggan divalidasi, kartu RFID dapat dikirimkan ke alamat pelanggan, dan pelanggan dapat langsung menggunakan kartu RFID tersebut. 
2. Dalam sistem pembayaran parkir, pelanggan diberi kemudahan untuk melakukan pembayaran dengan berbagai metode yaitu dapat melalui transfer via ATM maupun melalui sitem online (Ebanking/ mBanking).

Untuk meningkatkan kualitas pelayanan, perlu adanya pelatihan operator.

\section{UCAPAN TERIMAKASIH}

Penulis mengucapkan terima kasih kepada Instansi/perusahaan/lembaga yang telah memberi dukungan yang membantu pelaksanaan penelitian dan atau penulisan artikel.

\section{DAFTAR PUSTAKA}

[1] E. R., Sistem Informasi Manajemen, Jakarta: Mitra Wacana Media, 2016.

[2] B. O. Lubis, Sistem Informasi Penjualan Voucher Belanja Pada Pt. Plaza Indonesia Reality, Jakarta: Tbk. Jakarta Baginda. Informatika, 2016.

[3] H. Jogiyanto, Sistem Infomasi Manajemen, Banten: Universitas Terbuka, 2017.

[4] P. Y. E. Junianto, "Perancangan Sistem Tracking Invoice Laboraturium Pada Pt Sucufindo ( Persero ) Bandung," Jurnal Informatika, Pp. 442-452, 2015.

[5] R. Kusumaningtyas, "Evaluasi Dan Perancangan Sistem Informasi Lahan Parkir," Jurnal Sistem Informasi, Pp. 17-27, 2016.

[6] S. M. D. U. R. Hidayat, "Perancangan Sistem Informasi Penjualan Barang Handmade Berbasis Website Dengan Metode Waterfall,” Dalam Simnasiptek, Jakarta, 2017.

[7] K. J. K. Priyanto Hidayatullah, Pemrograman Web, Bandung: Informatika, 2014.

[8] S. Melanti, "Perancangan Sistem Informasi Akademik Berbasis Web Pada Smk Pasar Minggu Jakarta," Jurnal Informatika, P. 93, 2016.

[9] M. S. R. A.S., Rekayasa Perangkat Lunak Terstruktur Dan Berorientasi Objek, Bandung: Informatika, 2018.

[10] L. Setiyani, "Perancangan Sistem Informasi Pendidikan Dan Pelatihan (Diklat) Di Balai Besar Pelatihan Kesehatan Ciloto,” Jurnal Interkom, Pp. 20-27, 2018.

[11] A. H. A. Nugroho, "Perancangan Sistem Informasi Administrasi Jasa Foto Studi Literatur Pengumpulan Data Analisis Masalah Sistem Perancangan Sistem Pembuatan Laporan," Jurnal Ilmiah Media Processor, Pp. 200-209, 2014. 